\title{
New Data on the Intraindividual Variation of Cystatin C
}

\author{
Pierre Delanaye $^{\mathrm{a}}$ Etienne Cavalier $^{\mathrm{b}}$ Gisèle Depas $^{\mathrm{c}} \quad$ Jean-Paul Chapelle $^{\mathrm{b}}$ Jean-Marie Krzesinski ${ }^{\mathrm{a}}$ \\ Departments of ${ }^{a}$ Nephrology, ${ }^{b}$ Clinical Chemistry, and ${ }^{c}$ Nuclear Medicine, University of Liège, CHU Sart Tilman, Liège, Belgium
}

\begin{abstract}
Background: Cystatin $\mathrm{C}$ is a new interesting marker of glomerular filtration rate (GFR). However, data regarding its bio-logicalVariance are scarce and conflicting. The ability of cystatin $\mathrm{C}$ to longitudinally follow renal function in patients therefore remains questionable. Methods: 12 healthy subjects ( 6 men and 6 women) were included in the final statistical analysis. Serum creatinine, plasma cystatin C and GFR were measured twice after a 1-week interval on the same day, at the same time, and under the same preanalytical and analytical conditions. GFR was measured with an iohexol method. Serum creatinine was measured with a compensated Jaffé and an enzymatic method. Plasma cystatin $\mathrm{C}$ was measured by a particle-enhanced immunonephelometric method. Analytical $\left(\mathrm{CV}_{\mathrm{A}}\right)$ and within-subject $\left(\mathrm{CV}_{\mathrm{I}}\right)$ variances were classically calculated. Results: $\mathrm{CV}_{\mathrm{A}}$ for creatinine (Jaffé and enzymatic methods) and cystatin $\mathrm{C}$ was $2.5,0.97$ and $1.29 \%$, respectively. $\mathrm{CV}_{\mathrm{I}}$ was $5.8,5$ and $4.5 \%$ for the Jaffé creatinine, enzymatic creatinine and cystatin $\mathrm{C}$ determinations, respectively. Conclusion: Our study confirms that intraindividual variation of cystatin $\mathrm{C}$ and creatinine are similar. Therefore, from a biological point of view, cystatin $\mathrm{C}$ seems as accurate as creatinine for the longitudinal follow-up of renal function in daily clinical practice.
\end{abstract}

Keywords: Cystatin $\mathrm{C} \cdot$ Creatinine $\cdot$ Glomerular filtration rate

\section{Introduction}

Cystatin $\mathrm{C}$ and cystatin C-based equations are presented as interesting new biological variables for the detection of chronic renal failure and the estimation of glomerular filtration rate (GFR) [1]. Some authors have also suggested that cystatin $\mathrm{C}$ is of interest as a cardiovascular risk factor [2]. Nevertheless, this new marker is not free from criticism. Especially cystatin $\mathrm{C}$ concentrations seem to be dependent from thyroid status, steroids therapy and even muscular mass [3-5]. Moreover, the majority of the studies on cystatin $\mathrm{C}$ were transversal with very few longitudinal studies [6]. In the context of longitudinal studies, the determination of the biological variation (and especially intraindividual variation) of cystatin $\mathrm{C}$ is of importance. Until now, such data in adults are scarce and conflicting in the literature [1]. In the most cited article on this topic, Keevil et al. [7] described an intraindividual variation $\left(\mathrm{CV}_{\mathrm{I}}\right.$ for within-subject variance) as high as $13.3 \%$ in healthy adult subjects, although others found a $\mathrm{CV}_{\mathrm{I}}$ of $4.55 \%$ [8]. Yet other authors have found $\mathrm{CV}_{\mathrm{I}}$ under $5 \%$, but the methodologies, when described, were different (including non-healthy diabetics for example) $[1,9,10]$.

The aim of our study was to check and compare intraindividual variation of cystatin $\mathrm{C}$ and creatinine in a healthy adult population.

\section{Methods}

Thirteen healthy volunteers participated in the study (nurses and doctors from our dialysis and clinical chemistry hospital staffs); 7 men and 6 women, mean age of $38 \pm 8$ years, were included. They were neither obese nor hypertensive and were non-smokers. Samples and GFR measurements were collected twice after a 1-week interval at the same time each day $(08: 00 \mathrm{~h})$. Plasma cystatin $\mathrm{C}$ was measured using the particle-enhanced immunonephelometry method provided by Dade-Behring (Marburg, Germany). Serum creatinine was measured by the kinetic rate-blanked compensated Jaffé method on Modular and by the Roche enzymatic method on Hitachi (Roche Diagnostics, Mannheim, Germany). All samples were conserved at $-20^{\circ} \mathrm{C}$. The reference method for GFR measurement was based on plasma clearance of iohexol [11]. GFR was calculated from two samples at 120 and $240 \mathrm{~min}$ (slope-intercept method) as described by Brochner-Mortensen [12] (all samples were measured in duplicate). Subjects were in a fasting condition and invited to drink $1.51 \mathrm{of}$ water over $4 \mathrm{~h}$ after the iohexol injection. One patient (a 26-year-old male) had a GFR variation of 17\% between the two measurements. He was interviewed and admitted having done active exercises the evening beforehand in the first, but not in the second 
week. This probably explains the abnormally high variability of the GFR in this subject. He was then excluded from the statistical analysis which finally included 12 subjects ( 6 men and 6 women). According to Fraser and Harris [13], intraindividual variation of each marker was analyzed by calculating analytical $\left(\mathrm{SD}_{\mathrm{A}}{ }^{2}\right)$ and withinsubject $\left(\mathrm{SD}_{\mathrm{I}}{ }^{2}\right)$ variances. $\mathrm{SD}_{\mathrm{A}}{ }^{2}$ was calculated from the difference between duplicate results for each specimen of the first week $\left(\mathrm{SD}_{\mathrm{A}}{ }^{2}=\sum \mathrm{d}^{2} / 2 \mathrm{n}\right.$, where $d$ is the difference between duplicates, and $\mathrm{n}$ is the number of paired results). We obtained $\mathrm{SD}_{\mathrm{I}}^{2}$ (and thus $\mathrm{CV}_{\mathrm{I}}$ ) by subtraction of $\mathrm{SDA}^{2}$ from the observed variance noted within subjects between the 2 weeks.

\section{Results}

Table 1 shows the mean values of serum creatinine, plasma cystatin $\mathrm{C}$ and GFR observed during the first week of our study and a summary of the CV results.

Table 1: Summary of the CV results

\begin{tabular}{|c|c|c|c|c|}
\hline & $\begin{array}{c}\text { Jaffé creatinine } \\
\mathrm{mg} / \mathrm{dl}\end{array}$ & $\begin{array}{c}\text { Enzymatic } \\
\text { creatinine, } \mathrm{mg} / \mathrm{dl}\end{array}$ & $\begin{array}{c}\text { Cystatin C } \\
\mathrm{mg} / 1\end{array}$ & $\begin{array}{c}\text { GFR } \\
\mathrm{ml} / \mathrm{min}\end{array}$ \\
\hline Mean & 0.93 & 0.89 & 0.67 & 111 \\
\hline SD & 0.19 & 0.2 & 0.07 & 20 \\
\hline $\mathrm{CV}_{\mathrm{A}}$ & $2.5 \%$ & $0.97 \%$ & $1.29 \%$ & \\
\hline $\mathrm{CV}_{\mathrm{I}}$ & $5.8 \%$ & $5 \%$ & $4.5 \%$ & \\
\hline
\end{tabular}

\section{Discussion}

The analytical variances $\left(\mathrm{CV}_{\mathrm{A}}\right)$ obtained for creatinine measurement were therefore excellent and similar to those usually described in the literature ( 0.97 and $2.5 \%$ for the enzymatic and the Jaffé method, respectively) [1]. With the nephelometric method, our $\mathrm{CV}_{\mathrm{A}}$ for the cystatin $\mathrm{C}$ was as low as $1.29 \%$. This is similar to what other authors have described [9]. It must be noted that this $\mathrm{CV}_{\mathrm{A}}$ is slightly better than the $\mathrm{CV}$ described with the turbidi-metric method $[1,7,10]$. Imprecision for an analytical method can be defined as minimal, desirable or optimal in function of the biological variation of the parameter studied $\left(\mathrm{CV}_{\mathrm{A}}<0.75,<0.5\right.$ or $<0.25 \mathrm{CV}_{\mathrm{I}}$, respectively) [14]. Considering our $\mathrm{CV}_{\mathrm{I}}$ results, desirable and optimal performances for imprecision of cystatin $\mathrm{C}$ with the DadeBehring method should be 2.25 and $1.13 \%$ respectively. Creatinine determined with the Jaffé method should have a desirable and optimal imprecision of 2.9 and $1.45 \%$ respectively, whereas the desirable and optimal CV of the enzymatic method should be 2.5 and $1.25 \%$. Our analytical data on imprecision show that the performance of the Dade-Behring cystatin C (1.29\%) and the Jaffé method (2.5\%) are comprised between the optimal and desirable performance. Performance of the enzymatic method $(0.97 \%)$ can be considered as optimal.

$\mathrm{CV}_{\mathrm{I}}$ observed for creatinine was 5.8 and $5 \%$ for the Jaffé and the enzymatic methods, respectively. Once again, these results were not different to those found in the literature $[1,7,10]$. For the cystatin $C$, we found a $\mathrm{CV}_{I}$ of 4.5\%. This value is not significantly different to the $\mathrm{CV}_{\mathrm{I}}$ of the creatinine. Our results are therefore quite different to those noted by Keevil et al. [7] who found a $\mathrm{CV}_{\mathrm{I}}$ as high as $13.3 \%$ for the cystatin $\mathrm{C}$. The population we studied was relatively similar to that of Keevil et al. (healthy adult subjects), but, contrary to their study, we used a nephelometric method for cystatin $\mathrm{C}$ measurement (Keevil et al. used a turbidimetric method) but analytical differences can, of course, not explain the results obtained in intraindividual variance. More importantly, contrary to Keevil et al., we also measured the intraindividual variation of GFR, which was $4.5 \%$. The latter is of importance because the high $\mathrm{CV}_{\mathrm{I}}$ obtained by Keevil et al. may, as suggested by the authors themselves, be due to the variance of the GFR itself. The higher $\mathrm{CV}_{\mathrm{I}}$ for cystatin could thus reflect the better relationship between GFR and cystatin than between creatinine and GFR. From this point of view, our results are stronger because we have measured the total variance of GFR. This GFR measurement has allowed us to exclude patients with a significant GFR variance and to be sure that the intraindividual variation of our renal markers was not influenced by an abnormally high variation of the GFR itself, as was the case for one of our subjects. The fact that we measure GFR is the strength of our study but it is also the main limitation. Indeed, from a strict point of view, $\mathrm{CV}_{\mathrm{I}}$ must be calculated from ten points with 2-week intervals. Sensu stricto, our study has determined the reproducibility of cystatin $\mathrm{C}$ more than biological variability. Once again, we do not want to measure 'renal function-linked variability' of cystatin $\mathrm{C}$ but the true biological variability of this marker which imposes to exclude patients with abnormal GFR variability and thus to measure true GFR. However, measuring GFR ten times within 2 weeks is practically and ethically impossible (risk of hypersensitivity to iohexol and risk associated with numerous phlebotomies), and, as other authors, we have limited our data to two measurements 
[10]. Our sample may be viewed as limited $(n=13)$ but our population was homogenous and healthy. Observing our $\mathrm{CV}_{\mathrm{I}}$ results $(4.5 \%$ for cystatin $\mathrm{C}$ and $5 \%$ for cystatin $\mathrm{C})$, a more important sample $(\mathrm{n}=50)$ would certainly not permit to show a significant difference. Recently, Bandaranayake et al. [8] described $\mathrm{CV}_{\mathrm{I}}$ of $4.55 \%$ for cystatin $\mathrm{C}$ in healthy subjects using the same methodology as Keevil et al. [7] except that cystatin $\mathrm{C}$ was measured by immunonephelometry (but once again, the difference in analytical method cannot fully explain the difference in intraindividual variability). This last result is thus confirmed by our study where, once again, we have the strong advantage to measure the GFR variability.

From an analytical and biological point of view, our data allow to definitively conclude that plasma cystatin $\mathrm{C}$ seems at least as good as serum creatinine for the longitudinal follow-up of renal function. Nevertheless, due to other potential problems than analytical limitations of this marker [4, 5], the definitive superiority of cystatin $\mathrm{C}$ over creatinine must still be confirmed notably in longitudinal studies. Moreover, with our data, the critical difference $\left(=2.27 \times\left(\mathrm{CV}_{\mathrm{A}}^{2}+\mathrm{CV}_{\mathrm{I}}^{2}\right)^{0.5}\right)$, defined as the smallest change in results which is not due to chance, remains relatively high for cystatin and similar to enzymatic creatinine (13 and 14\%, respectively). As the relationship between GFR and creatinine or cystatin $\mathrm{C}$ is exponential, this fact will still be a limitation factor for the estimation of GFR in normal range $\left(>60 \mathrm{ml} / \mathrm{min} / 1.73 \mathrm{~m}^{2}\right)$ with both creatinine- and cystatin C-based equations [15].

\section{Acknowledgements}

The authors thank Mrs Rosalie Bonmariage for editing the manuscript. We also thank the nurses and doctors who were prepared to participate in the study. We especially thank the nurses of the Nuclear Medicine who realized all the samples.

\section{References}

1 Newman DJ: Cystatin C. Ann Clin Biochem 2002;39:89-104.

2 Shlipak MG, Sarnak MJ, Katz R, Fried LF, Seliger SL, Newman AB, Siscovick DS, Stehman-Breen C: Cystatin C and the risk of death and cardiovascular events among elderly persons. N Engl J Med 2005;352:2049-2060.

3 Bokenkamp A, Domanetzki M, Zinck R, Schumann G, Byrd D, Brodehl J: Cystatin C serum concentrations underestimate glomerular filtration rate in renal transplant recipients. Clin Chem 1999;45:1866-1868.

4 Jayagopal V, Keevil BG, Atkin SL, Jennings PE, Kilpatrick ES: Paradoxical changes in cystatin C and serum creatinine in patients with hypo- and hyperthyroidism. Clin Chem 2003;49:680-681.

5 Macdonald J, Marcora S, Jibani M, Roberts G, Kumwenda M, Glover R, Barron J, Lemmey A: GFR estimation using cystatin C is not independent of body composition. Am J Kidney Dis 2006;48:712-719.

6 Perkins BA, Nelson RG, Ostrander BE, Blouch KL, Krolewski AS, Myers BD, Warram JH: Detection of renal function decline in patients with diabetes and normal or elevated GFR by serial measurements of serum cystatin C concentration: results of a 4-year follow-up study. J Am Soc Nephrol 2005; 16: 1404-1412.

7 Keevil BG, Kilpatrick ES, Nichols SP, Maylor PW: Biological variation of cystatin C: implications for the assessment of glomerular filtration rate. Clin Chem 1998;44:1535-1539.

8 Bandaranayake N, Ankrah-Tetteh T, Wijer-atne S, Swaminathan R: Intra-individual variation in creatinine and cystatin C. Clin Chem Lab Med 2007;45:1237-1239.

9 Hoek FJ, Kemperman FA, Krediet RT: A comparison between cystatin C, plasma creatinine and the Cockcroft and Gault formula for the estimation of glomerular filtration rate. Nephrol Dial Transplant 2003;18:2024-2031.

10 Tan GD, Lewis AV, James TJ, Altmann P, Taylor RP, Levy JC: Clinical usefulness of cystatin C for the estimation of glomerular filtration rate in type 1 diabetes: reproducibility and accuracy compared with standard measures and iohexol clearance. Diabetes Care 2002;25:2004-2009.

11 Krutzen E, Back SE, Nilsson-Ehle I, Nilsson-Ehle P: Plasma clearance of a new contrast agent, iohexol: a method for the assessment of glomerular filtration rate. J Lab Clin Med 1984;104:955-961.

12 Brochner-Mortensen J: A simple method for the determination of glomerular filtration rate. Scand J Clin Lab Invest 1972;30:271-274 
Published in: Nephron. Clinical Practice (2008), vol. 108, iss. 4, pp. c246-c248

Status: Postprint (Author's version)

13 Fraser CG, Harris EK: Generation and application of data on biological variation in clinical chemistry. Crit Rev Clin Lab Sci 1989;27:409-437.

14 Fraser CG, Petersen PH: Analytical performance characteristics should be judged against objective quality specifications. Clin Chem 1999;45:321-323.

15 Delanaye P, Cavalier E, Krzesinski JM, Chapelle JP: Why the MDRD equation should not be used in patients with normal renal function (and normal creatinine values)? Clin Nephrol 2006;66:147-148. 